УДК 669.017:620.17

DOI: 10.30838/J.BPSACEA.2312.231018.25.307

\title{
ДО ПРОГНОЗУ МЕХАНІЧНИХ ВЛАСТИВОСТЕЙ МЕТАЛУ
}

ВОЛЧУК В. М. ${ }^{1}$, д-р техн. наук, проф., CI3OBA O. P. ${ }^{2}$, cmyd.

${ }^{1}$ Кафедра матеріалознавства та обробки матеріалів, Державний вищий навчальний заклад «Придніпровська державна академія будівництва та архітектури», вул. Чернишевського, 24-a, 49600, Дніпро, Україна, тел. +38 (0562) 47-39-56, e-mail: volchuky@gmail.com, ORCID ID: 0000-0001-7199-192X

${ }^{2}$ Кафедра матеріалознавства та обробки матеріалів, Державний вищий навчальний заклад »Придніпровська державна академія будівництва та архітектури», вул. Чернишевського, 24-a, 49600, Дніпро, Україна, тел. +38 (0562) 47-39-56, e-mail: 00lena00@ro.ru

Анотація. Bcmyn. Прогнозування механічних властивостей металевих виробів зумовлене труднощами, пов'язаними 3 впливом багатьох факторів. Основні 3 них - багатопараметричність та багатокритеріальність технології виробництва. Для зменшення витрат на натурні експерименти запропоновано методику оцінювання механічних властивостей металу з використанням математичного апарату. Методика. Застосовується математичне планування експериментів для оцінювання межі міцності сталі Ст4кп на основі аналізу елементів їі хімічного складу. Результати експерименту. Отримано математичну модель прогнозу межі міцності сталі Ст4кп, що дозволяє здійснювати її прогноз на заданому інтервалі показників хімічного складу. Згідно з критерієм Фішера $\mathrm{F}=1,187$ модель адекватна за рівня значимості $\alpha=0,05$. Висновки. В рамках методики планування експериментів отримано модель прогнозування межі міцності сталі Ст4кп, що дозволяє оперативно прогнозувати якість металу неруйнівним методом. Цей підхід можна застосовувати як експрес-методику оцінювання критеріїв якості металопрокату.

Ключові слова: планування експерименту; метал; хімічний склад; прогнозування; механічні властивості

\section{К ПРОГНОЗУ МЕХАНИЧЕСКИХ СВОЙСТВ МЕТАЛЛА}

\author{
ВОЛЧУК В. Н. ${ }^{1}$, д-р техн. наук, проф.,
}

СИЗОВА Е. Р. ${ }^{2}$, cmyд.

${ }^{1}$ Кафедра материаловедения и обработки материалов, Государственное высшее учебное заведение «Приднепровская государственная академия строительства и архитектуры», ул. Чернышевского, 24-a, 49600, Днипро, Украина, тел. +38 (0562) 47-39-56, e-mail: volchuky@gmail.com, ORCID ID: 0000-0001-7199-192X

${ }^{2}$ Кафедра материаловедения и обработки материалов, Государственное высшее учебное заведение «Приднепровская государственная академия строительства и архитектуры», ул. Чернышевского, 24-a, 49600, Днипро, Украина, тел.+38 (0562) 47-39-56, e-mail:00lena00@ro.ru

Аннотация. Введение. Прогнозирование механических свойств металлических изделий обусловлено трудностями, связанными с влиянием многих факторов. Основными из факторов являются многопараметричность и многокритериальность технологии производства. Для уменьшения затрат на натурные эксперименты предложена методика оценки механических свойств металла с использованием математического аппарата. Методика. Применяется математическое планирование экспериментов для оценки предела прочности стали Ст4кп на основе анализа элементов ее химического состава. Результаты эксперимента. Получена математическая модель прогноза предела прочности стали Ст4кп, что позволяет осуществлять его прогноз на заданном интервале показателей химического состава. Согласно критерию Фишера $\mathrm{F}=1,187$ модель адекватна при уровне значимости $\alpha=0,05$. Bbыводы. В рамках методики планирования экспериментов получена модель прогнозирования предела прочности стали Ст4кп, что позволяет оперативно прогнозировать качество металла неразрушающим методом. Данный подход можно применять в качестве экспресс-методики оценки критериев качества металлопроката.

Ключевые слова: планирование эксперимента; металл; химический состав; прогнозирование; механические свойства

\section{TO THE FORECAST OF MECHANICAL PROPERTIES OF METAL} VOLCHUK V. M. ${ }^{1}$, Dr. Sc. (Tech.), Prof., SIZOVA O. R. ${ }^{2}$, student

${ }^{1}$ Department of Materials Science, State Higher Educational Establishment «Prydniprovs'ka State Academy of Civil Engineering and Architecture», 24-a, Chernyshevskoho str., Dnipro, 49600, Ukraine, tel. +38 (0562) 47-39-56, e-mail: volchuky@gmail.com, ORCID ID: 0000-0001-7199-192X

${ }^{2}$ Department of Materials Science, State Higher Educational Establishment «Prydniprovs'ka State Academy of Civil Engineering and Architecture», 24-a, Chernyshevskoho str., Dnipro, 49600, Ukraine, tel. +38 (0562) 47-39-56, e-mail: 00lena00@ro.ru 
Annotation. Introduction. Forecasting the mechanical properties of metal products is due to the difficulties associated with the influence of many factors. The main factors are the multi-parameter and multi-criteria technology of production. A technique for evaluating the mechanical properties of a metal using a mathematical apparatus for reducing the cost of full-scale experiments is proposed. Methodology. Mathematical planning of experiments is used to evaluate the strength limit of steel type St4kp based on the analysis of the elements of its chemical composition. Results of the experiment. A mathematical model of the strength limit prediction of steel type St $4 \mathrm{kp}$ is obtained, which makes it possible to carry out its prediction on a given range of chemical composition indicators. According to the F-test, $\mathrm{F}=1.187$ is the model that is adequate at a significance level of $\alpha=0,05$. Conclusions. In the framework of the experiment planning methodology, a model for predicting the strength limit of steel type St4kp has been obtained, which makes it possible quickly predict the quality of the metal by a non-destructive method. This approach can be used as an express methodology for assessing the quality criteria of metal rolling.

Keywords: experiment planning; metal; chemical composition; forecasting; mechanical properties

Вступ. Для прогнозування механічних властивостей металопрокату нині застосовуються різні методики. Серед них окремо можна відмітити математичні методи [1-5], зокрема, теорії фракталів та мультифракталів [6-10], неруйнівні методи контролю [11]. Всі вони застосовуються для кожного конкретного випадку окремо залежно від поставленої мети. Труднощі вибору тієї чи іншої моделі для оцінювання критеріїв якості сталей та чавунів пов'язані в першу чергу з багатопараметричністю та багатокритеріальністю технології їх виробництва і впливом різних факторів $[12,13]$. Сюди слід віднести вплив хімічного складу та структури на властивості матеріалу [14].

Особливо слід відмітити математичні методики оцінювання критеріїв якості різ- них матеріалів. Їх застосування для прогнозу властивостей металів особливо актуальне, оскільки для їх визначення неможливо застосувати детермінований підхід, що базується на причинно-наслідкових зв'язках. Серед існуючих методик методика планування експериментів особливо часто використовується для прогнозу того чи іншого складного об'єкта дослідження.

Оцінювання критеріїв якості сталей 3 точністю, що може задовольняти вимогам замовника та нормативним документам, запропоновано проводити 3 допомогою методики планування експериментів.

Методика. Досліджувався вплив хімічного складу сталі Ст4кп на іï межу міцності (табл. 1).

Хімічний склад сталі 4кп

\begin{tabular}{|c|c|c|c|c|c|c|c|c|c|c|}
\hline $\begin{array}{c}\text { Вміст в \% } \\
\text { відповідно до } \\
\text { маси }\end{array}$ & $\mathrm{C}$ & $\mathrm{Si}$ & $\mathrm{Mn}$ & $\mathrm{Ni}$ & $\mathrm{S}$ & $\mathrm{P}$ & $\mathrm{Cr}$ & $\mathrm{N}$ & $\mathrm{Cu}$ & $\mathrm{As}$ \\
\hline Ст4кп & 0,18 & до & $0,40-$ & до & до & до & до 0,3 & до & до & до \\
& $-0,27$ & 0,05 & 0,70 & 0,3 & 0,05 & 0,05 & 0,008 & 0,3 & 0,08 \\
\hline
\end{tabular}

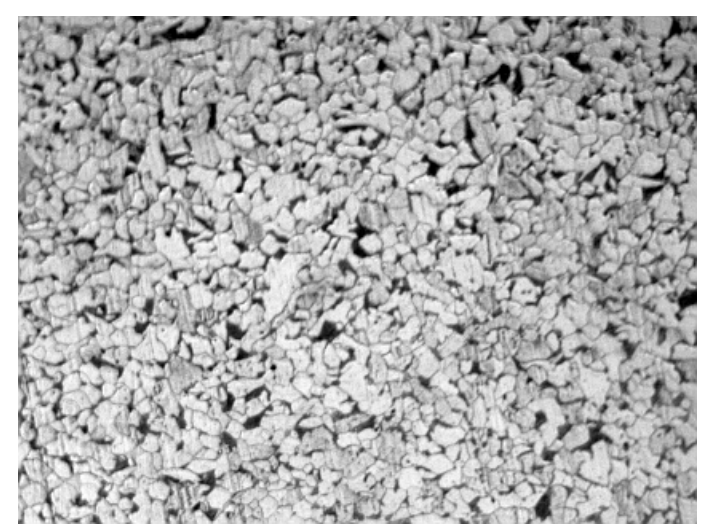

Рис. Мікроструктура сталі 4кп, збільшення 100

Межа міцності визначалася для труб у стані заводської поставки відповідно до ГОСТ 535-2005. Згідно з нормативними документами показники міцності становлять 400...510 МПа.

Сталь 4кп у стані заводської поставки має феритно-перлітну структуру (див. рисунок). Перліт розміщується по межах зерен фериту, його вміст у досліджуваних мікроструктурах сталі 4кп становив за підрахунками 25-30 \%.

Результати експерименту. В таблиці 2 наведено матрицю планування експериментів для сталі Ст4кп 3 експериментальними

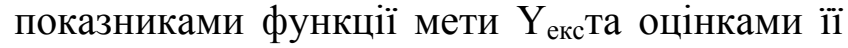


прогнозу $\mathrm{Y}_{\text {роз }}$, що розраховувалися за допомогоюрівняння регресії (1).

$$
\begin{aligned}
\mathrm{Y}_{\mathrm{po3}}= & 243,79+477,78 \cdot \mathrm{X}_{1}+1216,67 \cdot \mathrm{X}_{2}+ \\
& +95 \cdot \mathrm{X}_{3}+600 \cdot \mathrm{X}_{4} \quad\left(\mathrm{R}^{2}=0,89\right)
\end{aligned}
$$

У матриці планування експерименту загальний рівень (ЗР), інтервал варіювання (IB), нижній рівень (НР) та верхній рівень (BР) числових значень змінних (елементів хімічного складу) вибирались згідно 3 експертною оцінкою.

Таблиия 2

\begin{tabular}{|c|c|c|c|c|c|c|c|}
\hline & & & & & & & \\
\hline $3 \mathrm{P}$ & & 0,225 & 0,035 & 0,55 & 0,035 & & \\
\hline IB & & 0,045 & 0,015 & 0,15 & 0,015 & & цності \\
\hline $\mathrm{BP}$ & & 0,27 & 0,05 & 0,7 & 0,05 & & \\
\hline HP & & 0,18 & 0,02 & 0,4 & 0,02 & & \\
\hline № & $\mathrm{X}_{0}$ & $\mathrm{X}_{1}(\mathrm{C})$ & $\mathrm{X}_{2}(\mathrm{Si})$ & $\mathrm{X}_{3}(\mathrm{Mn})$ & $\mathrm{X}_{4}(\mathrm{Ni})$ & $\mathrm{Y}_{\text {екс }}$ & $Y_{\text {ро3 }}$ \\
\hline 1 & + & + & + & + & + & 520 & 530 \\
\hline 2 & + & + & + & + & - & 500 & 512 \\
\hline 3 & + & + & + & - & + & 505 & 502 \\
\hline 4 & + & + & + & - & - & 485 & 484 \\
\hline 5 & + & + & - & + & + & 498 & 494 \\
\hline 6 & + & + & - & + & - & 483 & 476 \\
\hline 7 & + & + & - & - & + & 478 & 465 \\
\hline 8 & + & + & - & - & - & 440 & 447 \\
\hline 9 & + & - & + & + & + & 488 & 487 \\
\hline 10 & + & - & + & + & - & 500 & 469 \\
\hline 11 & + & - & + & - & + & 460 & 459 \\
\hline 12 & + & - & + & - & - & 425 & 441 \\
\hline 13 & + & - & - & + & + & 440 & 451 \\
\hline 14 & + & - & - & + & - & 422 & 433 \\
\hline 15 & + & - & - & - & + & 420 & 422 \\
\hline 16 & + & - & - & - & - & 410 & 404 \\
\hline
\end{tabular}

Матриця планування експериментів

Для перевірки гіпотези про однорідність оцінок дисперсій використовували критерій Кохрена $G_{\max }[1]$, заснований на законі розподілу відношень максимальної емпіричної дисперсії $S_{\max }$ до суми всіх дисперсій (2):

$$
G_{\text {max }}=\frac{s_{g \text { max }}^{2}}{\sum_{g=1}^{N} s_{g}^{2}},
$$

де $s_{g}^{2}=\frac{1}{m-1} \sum_{l=1}^{m}\left(y_{g, l}-\bar{y}_{g}\right)^{2}$. При цьому $\mathrm{m}$ $=16$ - число паралельних дослідів; $y_{g, \digamma}$ по- точне значенняфункції; $\bar{y}_{g}-$ середнє значення функції. Невідтворюваність експериментів, як правило, є наслідком наявності неврахованих i, як результат, вплив неконтрольованих змінних, що створюють на виході об'єкта планування великий рівень «шуму».

Математична модель адекватна за критерієм Фішера $\mathrm{F}=1,187$ за рівня значимості $\alpha=0,05$. Аналіз рівняння регресії (1) підтверджує той факт, що найсильніший зв'язок спостерігається між функцією мети (показникомякості 
$Y)$ та аргументами $x_{1}$ (вуглець), $x_{2}$ (кремній) i $x_{4}$ (нікель). Це підтверджується найбільш високими серед розглянутих коефіцієнтами кореляції, що обгрунтовується фізикохімічною інтерпретацією їх впливу.

Висновки. Отримано регресійну модель прогнозу показників межі міцності сталі Ст4кп на основі аналізу впливу елементів ㄲi хімічного складу. Модель прогнозу якості металу адекватна за критерієм Фішера $\mathrm{F}=$ 1,187 за рівня значимості $\alpha=0,05$.

Запропонований підхід дозволяє оперативно та з мінімальними витратами прогнозувати якість металопрокату, що випускається 3 даної марки сталі, залежно від хімічного складу.

\section{СПИСОК ВИКОРИСТАНОЇ ЛІТЕРАТУРИ}

1. Вознесенский В. А. Статистические методы планирования эксперимента в технико-экономических исследованиях / В. А. Вознесенский. - Москва : Финансы и статистика, 1981. - 263 с.

2. Modified expanded clay lightweight concretes for thin-walled reinforced concrete floating structures / A. Mishutn, S. Kroviakov, O. Pishev, B. Soldo // Tehnicki Glasnik/Technical Journal. - 2017. - Vol. 11. - № 3. - P. 121-124. Режим доступу: https://hrcak.srce.hr/186657. - Перевірено: 07.02.2019.

3. Алгоритм проведения первичной статистической обработки массивов экспериментальных данных / Д. В. Лаухин, А. В. Бекетов, Н. А. Ротт, В. Д. Лаухин // Вісник Придніпровської державної академії будівництва та архітектури. - Дніпро, 2017. - № 2. - С. 68-77.

4. Дубров Ю. И. Применение экспертной информации при формировании активного эксперимента в материаловедении / Ю. И. Дубров, В.Н.Волчук, В.И.Большаков // Моделирование и оптимизация в материаловедении : мат. 40-го междунар. семинара по моделированию и оптимизации композитов МОК'40, 25-26 апр. 2001 г. - Одесса : АстроПринт, 2001. - С. 25-26.

5. Композиция метода планирования экстремальных экспериментов и экспертной информации для формирования системы прогноза качества материалов / В.И.Большаков, В.Н.Волчук, Л. Н. Дейнеко, Ю. И. Дубров // Перспективные задачи инженерной науки : сб. науч. тр. междунар. конф. - Днепропетровск : GAUDEAMUS, 2001 - Вып. 2. - С. 203-208.

6. Bol'shakov V. Fractals and properties of materials : monograph / V. Bol'shakov, V. Volchuk, Yu. Dubrov. Saarbrücken : Lambert Academic Publishing, 2016. - 140 p. - Режим доступу: https://www.lappublishing.com/catalog/details/store/tr/book/978-3-330-01812-9/fractals-and-properties-ofmaterials?search=Fractals. - Перевірено: 07.02.2019.

7. Method of material quality estimation with usage of multifractal formalism / V. Volchuk, I. Klymenko, S. Kroviakov, M. Orešković // Tehnički glasnik-Technical Journal. - 2018. - Vol. 12. - № 2. - Р. 93-97. - Режим доступу: https://hrcak.srce.hr/202359. - Перевірено 7.02.2019.

8. Большаков В. И. Основы организации фрактального моделирования : монография / В. И. Большаков, В. Н. Волчук, Ю. И. Дубров. - Киев : Академпериодика, 2017. - 170 с.

9. Журавель I. М. Вибір налаштувань під час обчислення поля фрактальних розмірностей зображення / I. М. Журавель // Науковий вісник НЛТУ України : зб. наук. пр. / Нац. лісотехн. ун-т України. - Львів, 2018. - Т. 28. - № 2. - С. 159-163. - Режим доступу: https://doi.org/10.15421/40280230. - Перевірено: 07.02.2019.

10. Журавель І. М. Вимірювання усередненого розміру зерен металу з використанням фрактальної розмірності / І. М. Журавель, Л. М. Свірська // Фізико-хімічна механіка матеріалів. - 2010. - Т. 46. - № 3. - С. 126-128. Режим доступу: http://dspace.nbuv.gov.ua/handle/123456789/135345. - Перевірено 7.02.2019.

11. Білокур І. П. Елементи дефектоскопії при вивченні неруйнівного контролю : навч. посіб. / І. П. Білокур. - Київ : НМК BO, 1990. - 252 c.

12. Большаков В. И. О прогнозировании качества целевого продукта в периодических технологиях / В. И. Большаков, В. Н. Волчук, Ю. И. Дубров // Доповіді Національної академії наук України. - 2014. № 11. - С.77-81. - Режим доступу: http://www.dopovidi.nas.gov.ua/2014-11/14-11-13.pdf. -Перевірено: 07.02.2019.

13. Большаков В. И. Идентификация многопараметрических, многокритериальных технологий и пути их практической реализации / В. И. Большаков, В. Н. Волчук, Ю. И. Дубров // Металознавство та термічна обробка металів. - 2013. - № 4. - С. 5-11.

14. Investigation of Acicular Ferrite Structure and Properties of C-Mn-Al-Ti-N Steels / O. Uzlov, A. Malchere, V. Bolshakov, C. Esnouf // Advanced Materials Research. - 2007. - Vol. 23. - Р. 209-312. - Режим доступу: https://doi.org/10.4028/www.scientific.net/AMR.23.209. - Перевірено 7.02.2019. 


\section{REFERENCES}

1. Voznesenskiy V.A. Statisticheskiye metody planirovaniya eksperimenta $v$ tekhniko-ekonomicheskikh issledovaniyakh [Statistical methods of experiment planning in technical and economic research]. Moscow: Finansy i statistika, 1981, 263 p. (in Russian).

2. Mishutn A., Kroviakov S., Pishev O. and Soldo B. Modified expanded clay lightweight concretes for thin-walled reinforced concrete floating structures. Tehnicki Glasnik. Technical Journal. 2017, vol. 11, no. 3, pp. $121-124$. Available at: https://hrcak.srce.hr/186657. [Accessed 7 February 2019]. (in Russian).

3. Laukhin D.V., Beketov A.V., Rott N.A. and Laukhin V.D. Algoritm provedeniya pervichnoy statisticheskoy obrabotki massivov eksperimental'nykh dannykh [Algorithm of primary statistical analysis of arrays of experimental data]. Visnyk Prydniprovskoi derzhavnoi akademii budivnitstva ta arkhitektury [Bulletin of Prydniprovs'ka State Academy of Civil Engineering and Architecture]. Dnipro, 2017, no. 2, pp. 68-77. Available at: http://visnyk.pgasa.dp.ua/article/view/111314. [Accessed 7 February 2019]. (in Russian).

4. Dubrov Yu.I., Volchuk V.N. and Bol'shakov V.I. Primeneniye ekspertnoy informatsii pri formirovanii aktivnogo eksperimenta $v$ materialovedenii [Application of expert information in the formation of an active experiment in materials science]. Modelirovaniye $i$ optimizatsiya $v$ materialovedenii: mat. 40-go mezhdunar. seminara po modelirovaniyu $i$ optimizatsii kompozitov MOK'40 [The modeling and optimization in materials science. Proceedings of 40th Int. seminar on modeling and optimization of IOC'40 composites]. Odessa: AstroPrint, 2001, pp. 25-26. (in Russian).

5. Bol'shakov V.I., Volchuk V.N., Dejneko L.N. and Dubrov Yu.I. Kompozitsiya metoda planirovaniya ekstremal'nykh eksperimentov $i$ ekspertnoj informatsii dlya formirovaniya sistemy prognoza kachestva materialov [Composition of a method for planning extreme experiments and expert information for the formation of a material quality prediction system]. Perspektivnye zadachi inzhenernoj nauki [Perspective tasks of engineering science]. Dnepropetrovsk: GAUDEAMUS, 2001, iss. 2. pp. 203-208. (in Russian).

6. Bol'shakov V., Volchuk V. and Dubrov Yu. Fractals and properties of materials. Saarbrucken: Lambert Academic Publishing, 2016, 140 p. Available at: https:/www.lap-publishing.com/catalog/details/store/tr/book/978-3-33001812-9/fractals-and-properties-of-materials?search=Fractals. [Accessed 6 February 2019].

7. Volchuk V., Klymenko I., Kroviakov S., Orešković M. Method of material quality estimation with usage of multifractal formalism. Tehnički glasnik. Technical Journal. 2018, vol. 12, no. 2, pp. 93-97.

8. Bol'shakov V.I., Volchuk V.M. and Dubrov Yu.I. Osnovy organizatsii fraktal'nogo modelirovaniya [Fundamentals of fractal modeling]. Kiev: Akademperiodika, 2017, 170 p. (in Russian).

9. Zhuravel I.M. Vybir nalashtuvan pid chas obchyslennia polia fraktalnykh rozmirnostei zobrazhennia [The choice of parameters when calculating the fractal dimension of the image]. Naukovyi visnyk NLTU Ukrainy [Scientific Bulletin of UNFU]. Lviv, 2018, vol. 28, no 2, pp. 159-163. Available at: https://doi.org/10.15421/40280230. [Accessed 7 February 2019]. (in Ukrainian).

10. Zhuravel I.M. and Svirska L.M. Vymiriuvannia userednenoho rozmiru zeren metalu z vykorystanniam fraktalnoi rozmirnosti [Measurement of the mean grain size in a metal by using fractal dimensions]. Fizyko-khimichna mekhanika materialiv [Materials Science]. 2010, vol. 46, no 3, pp. 418-420. Available at: http://dspace.nbuv.gov.ua/handle/123456789/135345. [Accessed 7 February 2019]. (in Ukrainian).

11. Bilokur I.P. Elementy defektoskopii pry vyvchenni neruinivnoho kontroliu [Elements of defectoscopy during studying of non-destructive control]. Kyiv: NMK VO, 1990, 252 p. (in Ukrainian).

12. Bol'shakov V.I., Volchuk V.N. and Dubrov Yu.I. O prognozirovanii kachestva tselevogo produkta $v$ periodicheskikh tekhnologiyakh [Predicting the quality of a desired product in periodic technologies]. Dopovidi Natsionalnoi akademii nauk Ukrainy [Reports of the National Academy of Sciences of Ukraine]. Kyiv, 2014, no. 11, pp. 77-81. Available at: http://www.dopovidi.nas.gov.ua/2014-11/14-11-13.pdf. [Accessed 7 February 2019]. (in Russian).

13. Bol'shakov V.I., Volchuk V.N. and Dubrov Yu.I. Identifikatsiya mnogoparametricheskikh, mnogokriterial'nykh tekhnologiy i puti ikh prakticheskoy realizatsii [Multiparameter identification, multicriteria techniques and ways of their implementation]. Metaloznavstvo ta termichna obrobka metaliv [Metall Science and Heat Treatment of Metals]. 2013, no 4., pp. 5-11. (in Russian).

14. Uzlov O., Malchere A., Bolshakov V.I., Esnouf C. Investigation of Acicular Ferrite Structure and Properties of CMn-Al-Ti-N Steels. Advanced Materials Research. 2007, vol. 23, pp. 209-312. Available at: https://doi.org/10.4028/www.scientific.net/AMR.23.209. [Accessed 7 February 2019].

Рецензент: Дубров Ю. І., д-р техн. наук, проф.

Надійшла до редколегії: 10.07.2018 р. 